\title{
Is hysterectomy a risk factor for urinary incontinence?
}

\author{
Maria C. Alexander ${ }^{1}$, Vaibhav Londhe ${ }^{1 *}$, Emily D. Ebenezer ${ }^{1}$, \\ Aruna N. Kekre', Visalakshi Jeyaseelan ${ }^{2}$
}

\begin{abstract}
${ }^{1}$ Department of Obstetrics and Gynecology, ${ }^{2}$ Department of Biostatistics, Christian Medical College and Hospital, Vellore, Tamil Nadu, India
\end{abstract}

Received: 03 February 2019

Accepted: 11 March 2019

\section{*Correspondence:}

Dr. Vaibhav Londhe,

E-mail: vlondz@gmail.com

Copyright: (C) the author(s), publisher and licensee Medip Academy. This is an open-access article distributed under the terms of the Creative Commons Attribution Non-Commercial License, which permits unrestricted non-commercial use, distribution, and reproduction in any medium, provided the original work is properly cited.

\begin{abstract}
Background: Hysterectomy is the most common gynecological surgery performed. There are few studies evaluating hysterectomy as a risk factor for urinary incontinence. If hysterectomy is found to be a risk factor for developing urinary incontinence, women undergoing hysterectomy can be well informed prior to the procedure regarding the same. The objective of the present study was to study the prevalence of urinary incontinence in post-menopausal women and its relationship to hysterectomy. To evaluate the association of metabolic syndrome, to urinary incontinence.

Methods: This study was a prospective cohort study done in Christian Medical College and Hospital, Vellore, Tamil Nadu between December 2016- December 2017. Postmenopausal women both with natural and surgical menopause, were enrolled into the study after an informed consent. The UDI-6 questionnaire was used to assess urinary incontinence. The categorical variables were presented using frequencies and percentages. The comparison of categorical variables was done using Fisher's exact test. The odds ratio and confidence interval were calculated for the prevalence. $\mathrm{P}$ value $<0.05$ was considered to be statistically significant.

Results: A total of 600 women were enrolled into the study with 300 women having attained natural menopause and 300 women with a surgical menopause. The prevalence of urinary incontinence among these post-menopausal women was $46.24 \%$. The prevalence of urinary incontinence amongst the women with natural menopause was $47.3 \%$ and amongst the women with surgical menopause was $45 \%(\mathrm{p}=0.566)$. Women with metabolic syndrome suffered from urinary incontinence more than their counterparts without metabolic syndrome $(55.8 \%$ vs. $36 \%$, p <0.0001).

Conclusions: The prevalence of urinary incontinence in the natural menopause and surgical menopause groups was similar, thus proving that hysterectomy is not a risk factor for developing urinary incontinence. However, metabolic syndrome was found to be associated with urinary incontinence.
\end{abstract}

Keywords: Menopause, Metabolic syndrome, Obesity, Urinary incontinence

\section{INTRODUCTION}

Urinary incontinence is defined as involuntary leakage of urine, affecting quality of life. It can either be a stress urinary incontinence, urge urinary incontinence or a mixed type. Urinary incontinence affects women of all ages but is more prevalent in older women. The worldwide prevalence of urinary incontinence among postmenopausal women is around $30-50 \% .^{1}$ It is not a life-threatening condition but has a significant impact on the quality of life. Women are now living longer, demanding and deserving a good quality of life. The risk factors for urinary incontinence include age, parity, obesity, menopausal status and hysterectomy, of which 
obesity and hysterectomy are modifiable ones. Hysterectomy is one of the most common gynecological surgeries performed worldwide. However, very few studies have evaluated hysterectomy as a risk factor for urinary incontinence. ${ }^{1-10}$ The largest data available from the secondary analysis done on women who participated in the Women's health initiative trial (WHI trial), showed a positive association between hysterectomy and urinary incontinence. ${ }^{11}$ The Storage and voiding symptoms like frequency, urgency and urge incontinence increases around menopause. The cause for the same may be due to ageing, menopausal status or both. ${ }^{12}$ The decreasing levels of estrogen at menopause cause urogenital atrophy and decreased collagen synthesis thereby weakening the pelvic floor. ${ }^{12}$ Urinary incontinence after hysterectomy maybe due to lasting injury to the pelvic plexus at the time of uterosacral/cardinal ligament complex transection, bladder flap formation or possibly due to disruption of anatomical support to bladder neck and urethra. ${ }^{11}$ Our research will aim at providing data on the prevalence of urinary incontinence in postmenopausal women and establish the association between hysterectomy and urinary incontinence. For more practical and objective assessment, standardized questionnaires have been developed, tested and proven in terms of validity, accuracy and correlation with clinical examination. The route of hysterectomy has been evaluated in certain studies as an influencing factor for the incidence of urinary incontinence. ${ }^{13,14}$ Some studies have shown a higher incidence of urinary incontinence among women with vaginal hysterectomy while other studies have found no difference. Metabolic syndrome is an independent risk factor for urinary incontinence and there have been various studies proving the same. ${ }^{15-21}$ Since metabolic syndrome is widely prevalent among the Asian population, as a secondary outcome, authors looked into the association of metabolic syndrome with urinary incontinence. In this study, authors classified women as having metabolic syndrome as per the International Diabetes Federation (IDF) criteria. According to the new IDF definition, metabolic syndrome is diagnosed if the patient has central obesity, which is defined as waist circumference of $\geq 80 \mathrm{~cm}$ in females, plus any two of the following:

- $\quad$ Raised triglycerides $\geq 150 \mathrm{mg} / \mathrm{dl}$ or specific treatment for lipid abnormality

- Reduced HDL cholesterol $<50 \mathrm{mg} / \mathrm{dl}$ or specific treatment for lipid abnormality

- $\quad$ Raised blood pressure of systolic BP $\geq 130 \mathrm{~mm}$ of $\mathrm{Hg}$ or diastolic $\mathrm{BP} \geq 85 \mathrm{~mm}$ of $\mathrm{Hg}$ or treatment of previously diagnosed hypertension

- $\quad$ Raised fasting plasma glucose with FPG $\geq 100 \mathrm{mg} / \mathrm{dl}$ or previously diagnosed type 2 diabetes mellitus.

Using standardized questionnaires and physical examination women were diagnosed with urinary incontinence and its correlation with metabolic syndrome was evaluated.

\section{METHODS}

\section{Study setting}

This is a prospective cohort study done in Christian Medical College and Hospital, a tertiary care center in Vellore district of Tamil Nadu, in southern India between December 2016- December 2017 .The study was approved by the Institutional review board (IRB) and ethics committee with IRB no. 10432. Postmenopausal women both with natural and surgical menopause attending the Menopause clinic and Female Continence clinic during which time were enrolled into the study after a written informed consent.

\section{Inclusion criteria}

- Women over 45 years who had attained menopause either naturally or surgically.

- Hysterectomy was done for a benign gynecological condition at least 12 months or more prior to the hospital visit.

\section{Exclusion criteria}

- Post-menopausal women less than 45 years of age or who had undergone a hysterectomy for a malignancy.

The urinary distress inventory-6 (UDI 6) questionnaire was used to evaluate the presence of urinary incontinence. Complete pelvic examination was done to look for stress urinary incontinence if any.

\section{Sample size calculation}

As already mentioned above, the global prevalence of urinary incontinence among postmenopausal women varied in different studies from $18 \%$ to $50 \% .^{22,23}$ In a study by Singh et al the prevalence, was $20 \% .{ }^{24}$ Hence, using the lowest prevalence i.e. $18 \%$, the required sample size to show an odd of about 1.8 times of urinary incontinence across women with hysterectomy and women without a hysterectomy, was calculated to be around 600, with 300 women in each arm, with $80 \%$ power and $5 \%$ level of significance.

\section{Statistical analysis}

The mean with standard deviation or median with interquartile range were presented for all continuous variables. This summary measure was decided on the basis of distribution of each variable if they followed normal or not. The categorical variables were presented using frequencies and percentages. The comparison of categorical variables was done using Fisher's exact test, odds ratio and confidence interval were calculated for the prevalence. $\mathrm{P}$ value $<0.05$ was considered to be statistically significant. SPSS 16 was used for statistical analysis. 


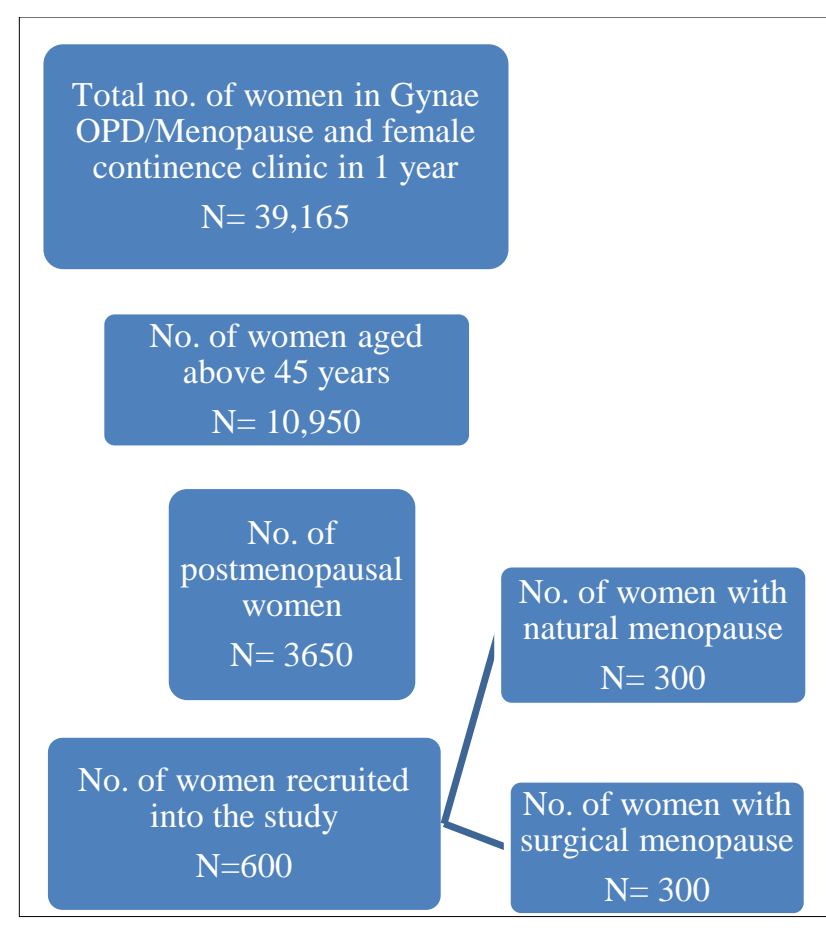

Figure 1: Sample size calculation.

\section{RESULTS}

A total of 600 women were recruited into the study, with 300 of them having attained natural menopause and the other 300 had undergone hysterectomy.

Table 1: Baseline characteristics of the study population.

\begin{tabular}{|l|l|l|l|}
\hline $\begin{array}{l}\text { Baseline } \\
\text { characteristics }\end{array}$ & $\begin{array}{l}\text { Menopause } \\
\text { Natural } \\
(\%)\end{array}$ & $\begin{array}{l}\text { Surgical } \\
(\%)\end{array}$ & P value \\
\hline $\begin{array}{l}\text { Age } \\
\leq 55\end{array}$ & $137(45.6)$ & $216(72)$ & $<0.0001$ \\
\hline $56-65$ & $118(39.3)$ & $61(20.3)$ & 0.01 \\
\hline $\begin{array}{l}\mathbf{\%} 6 \\
\text { Parity: }\end{array}$ & $45(15)$ & $23(7.6)$ & 0.38 \\
\hline Nulliparous & $17(5.6)$ & $9(3)$ & 0.76 \\
\hline Multiparous & $283(94.3)$ & $291(97)$ & 0.11 \\
\hline No. of vaginal deliveries & $265(88.3)$ & $270(90)$ & 0.52 \\
\hline At least one & $35(11.7)$ & $30(10)$ & 0.82 \\
\hline None & $16(5.3)$ & $16(5.3)$ & 1 \\
\hline Instrumental delivery & $284(94.7)$ & $284(94.7)$ & 1 \\
\hline Yes & $15(5)$ & $6(2)$ & 0.75 \\
\hline No & $102(34)$ & $105(35)$ & 0.87 \\
\hline BMI & $119(39.7)$ & $120(40)$ & 0.96 \\
\hline Underweight & $58(19.3)$ & $68(22.7)$ & 0.64 \\
\hline Normal & $6(2)$ & $1(0.3)$ & 0.86 \\
\hline $\begin{array}{l}\text { Overweight } \\
\text { Obese }\end{array}$ & & \\
\hline $\begin{array}{l}\text { Morbidly } \\
\text { obese }\end{array}$ & &
\end{tabular}

The baseline characteristics of the women in the two groups are given in Table 1. The two groups had women with similar parity status, number of vaginal deliveries, instrumental deliveries and BMI. However, the surgical menopause group had younger women than the natural menopause group. A total of 277 women experienced urinary incontinence giving a prevalence of urinary incontinence among menopausal women as $46.24 \%$ (Figure 2).

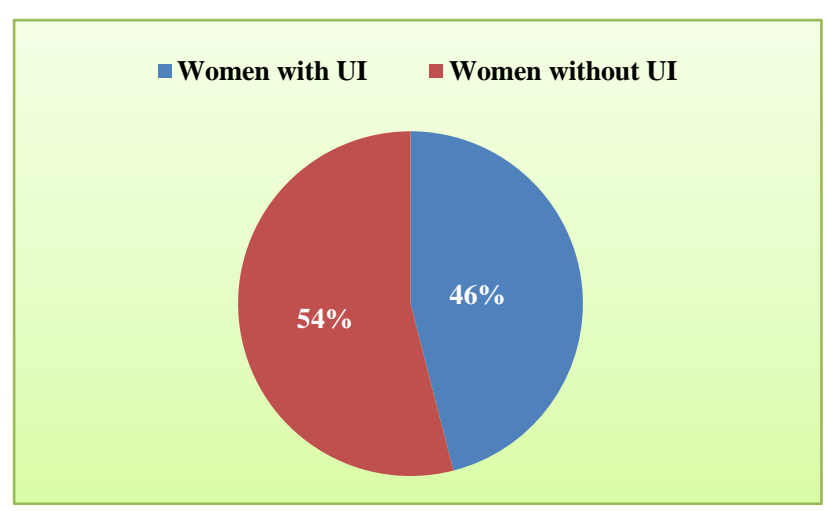

Figure 2: The prevalence of urinary incontinence among postmenopausal women.

142 women with natural menopause and 135 women with surgical menopause experienced urinary incontinence, as shown in Table 2 . There was no statistically significant difference in the prevalence of urinary incontinence in the two groups with an odds ratio of 0.91 (95\% CI 0.661.25).

Table 2: Correlation of urinary incontinence with the type of menopausal status.

\begin{tabular}{|l|l|l|l|}
\hline $\begin{array}{l}\text { Urinary } \\
\text { incontinence }\end{array}$ & $\begin{array}{l}\text { Natural } \\
\text { menopause }\end{array}$ & $\begin{array}{l}\text { Surgical } \\
\text { menopause }\end{array}$ & $\begin{array}{l}\text { p } \\
\text { value }\end{array}$ \\
\hline Yes & $142(47.3 \%)$ & $135(45 \%)$ & 0.566 \\
\hline No & $158(52.7 \%)$ & $165(55 \%)$ & 0.5 \\
\hline
\end{tabular}

$42 \%$ of women experienced stress urinary incontinence, $15 \%$ had urge urinary incontinence and $43 \%$ had mixed urinary incontinence as seen in Figure 3.

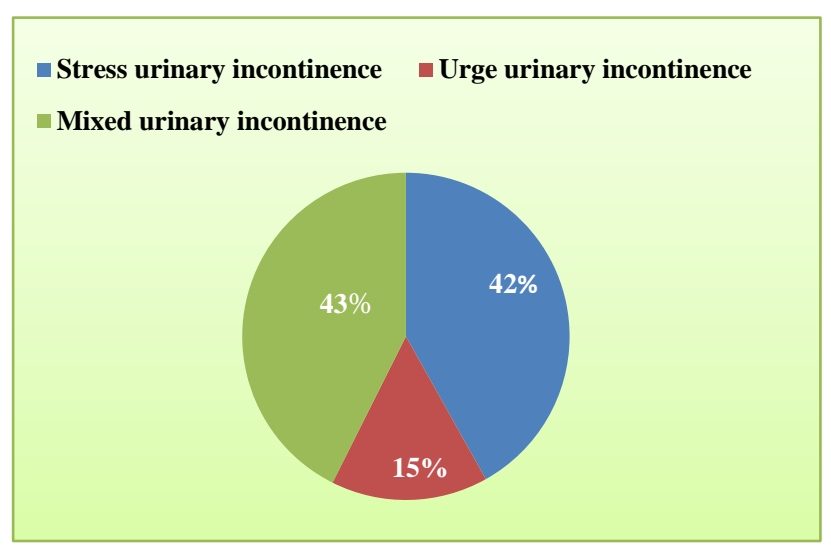

Figure 3: Types of urinary incontinence 
In women with natural menopause, $42.3 \%$ of women had stress urinary incontinence, $19.7 \%$ had urge urinary incontinence and $38 \%$ had mixed urinary incontinence. In women with surgical menopause, $41.5 \%$ had stress urinary incontinence, $11.1 \%$ had urge urinary incontinence and $47.4 \%$ had mixed urinary incontinence (Table 3).

\section{Table 3: Correlation of menopausal status with type} of urinary incontinence.

\begin{tabular}{|l|l|l|l|}
\hline & SUI $(\%)$ & UUI $(\%)$ & MUI (\%) \\
\hline Natural menopause & 42.3 & 19.7 & 38 \\
\hline Surgical menopause & 41.5 & 11.1 & 47.4 \\
\hline
\end{tabular}

$46.3 \%$ of women who underwent abdominal hysterectomy experienced urinary incontinence $(102 / 220)$, of which $46 \%(47 / 102)$ had stress urinary incontinence, $8 \%(8 / 102)$ had urge urinary incontinence and $46 \%(47 / 102)$ had mixed urinary incontinence. $42.8 \%$ of women who underwent vaginal hysterectomy experienced urinary incontinence (24/56), of which $33.3 \%(8 / 24)$ had stress urinary incontinence, $16.7 \%$ $(4 / 24)$ had urge urinary incontinence and $50 \%(12 / 24)$ had mixed urinary incontinence.

There were 24 women who underwent a laparoscopic hysterectomy, of which 9 of them experienced urinary incontinence $(37.5 \%)$ (Table 4). In this study authors found that an abdominal or a vaginal route of hysterectomy did not affect the prevalence of urinary incontinence $(\mathrm{p}=0.63)$.

Table 4: Correlation of route of hysterectomy with urinary incontinence.

\begin{tabular}{|l|c|c|c|c|}
$\begin{array}{l}\text { Route of } \\
\text { hysterectomy } \\
(\mathbf{n = 3 0 0 )}\end{array}$ & \multicolumn{4}{|c|}{ Type of incontinence } \\
\hline & $\begin{array}{l}\text { SUI } \\
(\boldsymbol{\%})\end{array}$ & $\begin{array}{c}\text { UUI } \\
(\boldsymbol{\%})\end{array}$ & $\begin{array}{l}\text { MUI } \\
(\boldsymbol{\%})\end{array}$ & $\mathbf{p}$ \\
\hline Abdominal (n=220) & 46 & 8 & 46 & \\
\hline Vaginal (n=56) & 33.3 & 16.7 & 50 & 0.63 \\
\hline Laparoscopic (n=24) & 11.1 & 33.3 & 55.6 & \\
\hline
\end{tabular}

Prevalence of urinary incontinence increased with increasing BMI and was highest among obese and morbidly obese women and this correlation was statistically significant $(\mathrm{p}=0.0001)$ (Table 5).

Table 5: Correlation of urinary incontinence to BMI.

\begin{tabular}{|l|l|l|l|}
\hline \multirow{2}{*}{ BMI } & \multicolumn{2}{|l|}{ Urinary incontinence } & \multirow{2}{*}{ p value } \\
\hline Underweight & $7(33.3)$ & $14(66.7)$ & \\
\hline Normal & $75(36.2)$ & $132(63.8)$ & \\
\hline Overweight & $114(47.6)$ & $125(52.4)$ & \multirow{2}{*}{0.0001} \\
\hline Obese & $74(61.8)$ & $52(38.2)$ & \\
\hline Morbidly obese & $7(100)$ & 0 & \\
\hline
\end{tabular}

Authors also looked at metabolic syndrome as a risk factor for urinary incontinence and found that women with metabolic syndrome suffered from urinary incontinence more than their counterparts without metabolic syndrome $(55.8 \% \mathrm{vs} 36 \%, \mathrm{p}<0.0001)$. This correlation was statistically significant (Table 6).

Table 6: Correlation of urinary incontinence to metabolic syndrome.

\begin{tabular}{|l|c|c|c|}
\multirow{2}{*}{$\begin{array}{l}\text { Urinary } \\
\text { incontinence }\end{array}$} & \multicolumn{2}{c}{ Metabolic syndrome } & \multirow{2}{*}{ p value } \\
\hline Yes & $146(55.8)$ & No $(\%)$ & \\
\hline No & $116(44.2)$ & $194(64)$ & $<0.0001$ \\
\hline
\end{tabular}

\section{DISCUSSION}

Urinary incontinence is a distressing condition though it is not life threatening but severely affects the quality of life. The worldwide prevalence of urinary incontinence among women was found to be around $50 \%$ which increased with advancing age. ${ }^{25}$ A recent postal survey by Louise et al conducted in Germany and Denmark, included 8000 female participants, showed a prevalence of $48.3 \%$ among responders from Germany and $46.4 \%$ among responders from Denmark. ${ }^{25,26}$ A Chinese study conducted in the Shanghai province had 5467 women older than 20 years of age recruited into the study reported a prevalence of $23.3 \%$ for urinary incontinence. Among these women, it was seen that stress urinary incontinence was more prevalent (14\%), than urge urinary incontinence $(3 \%)$ and mixed urinary incontinence $(6.3 \%)$. In the study by Singh A et al, the prevalence was $20.74 \%$ among postmenopausal women with stress urinary incontinence being more prevalent $(24.5 \%) .^{24}$

The prevalence of urinary incontinence among postmenopausal women in this study was $46 \%$, which was similar to the worldwide prevalence of $50 \% .{ }^{25}$ In this study mixed urinary incontinence predominated (43\%) followed by stress urinary incontinence $(42 \%)$. Studies done by Brown et al showed a prevalence of urinary incontinence among postmenopausal women to be $56 \%$, and Schreiber et al and Liu et al also showed a similar prevalence of around $48 \% .^{23,26,27}$

There are various studies done globally evaluating hysterectomy as a risk factor for urinary incontinence with conflicting results. The largest data available on this is the secondary analysis of women who participated in the Women's Health Initiative (WHI) trial. ${ }^{11}$ In the WHI study women who reported urinary incontinence after a hysterectomy was higher than in women who had a natural menopause, with an odds ratio of $1.25(95 \% \mathrm{CI}$ $1.19,1.32$ ). Hock et al, found a prevalence of $23.77 \%$ among surgical menopause women. ${ }^{28}$

Some studies showed a strong association however some studies showed no increased risk of urinary incontinence 
in women with hysterectomy. , $^{2,6,9,11,28-30}$ In the study by Hseih et al, the prevalence of urinary incontinence in Taiwanese women who had a surgical menopause was $42.38 \%$ and $27.96 \%$ among women with a natural menopause, thus proving that hysterectomy is a risk factor for urinary incontinence. ${ }^{6}$ However, in this study, the prevalence of urinary incontinence among women who had a surgical menopause was $45 \%$, which was similar to women who had a natural menopause $(47.3 \%)$, showing that hysterectomy is not a risk factor for developing urinary incontinence. Though the prevalence of urinary incontinence in women with a surgical menopause was similar as in the study by Hseih et al, the prevalence among women with natural menopause was much higher than in Hseih's study. ${ }^{6}$

The route of hysterectomy has been evaluated as an influencing factor in developing urinary incontinence. In the study by $\mathrm{A} \mathrm{El}$ et al, there was no difference in the prevalence of urinary incontinence in women who underwent an abdominal or a vaginal hysterectomy, while in the study by Pei et al they found a higher prevalence among women who underwent vaginal hysterectomy. ${ }^{13,14}$ In this study authors found no difference in the prevalence of urinary incontinence among women who underwent an abdominal and a vaginal hysterectomy ( $\mathrm{p}$ $=0.63$ ).

As a secondary outcome, authors looked into metabolic syndrome as a risk factor for urinary incontinence. The overall global data have shown a positive correlation between metabolic syndrome and urinary incontinence. ${ }^{19,20,29}$ Zacche et al, evaluated each component of the metabolic syndrome and found that obesity alone had a positive correlation with urinary incontinence, with an odds ratio of 1.09 (95\% CI 1.05$1.13) .^{29}$

In this study urinary incontinence was seen in $55.8 \%$ of women with metabolic syndrome, which was statistically significant when compared to women without metabolic syndrome with an odds ratio of 2.24 (95\% CI 1.59-3.14). In this study, obesity had a positive correlation with urinary incontinence. 126 women were obese $\left(\mathrm{BMI}>30 \mathrm{~kg} / \mathrm{m}^{2}\right)$ and 7 were morbidly obese $\left(>35 \mathrm{~kg} / \mathrm{m}^{2}\right)$. Among these women, $61 \%$ experienced urinary incontinence which was statistically significant ( $<0.0001)$.

\section{CONCLUSION}

The overall prevalence of urinary incontinence among postmenopausal women is $46 \%$. The prevalence of urinary incontinence in the natural menopause $(47.3 \%)$ and surgical menopause $(45 \%)$ groups was similar thus proving that hysterectomy is not a risk factor for developing urinary incontinence (OR 0.91 (95\% CI 0.661.25). Obesity was found to be strongly associated with urinary incontinence and more so when the woman was morbidly obese, with a prevalence of $61 \%$. The route of hysterectomy, whether abdominal or vaginal, did not influence the incidence of urinary incontinence. With increasing BMI, the prevalence of urinary incontinence increased, and it was statistically significant $(\mathrm{p}=0.0001)$. Metabolic syndrome was also found to be associated with urinary incontinence with a prevalence of urinary incontinence being $55.8 \%$ among women with metabolic syndrome which was much higher than in women without a metabolic syndrome (OR 2.24, 95\% CI 1.59-3.14).

\section{Funding: No funding sources}

Conflict of interest: None declared

Ethical approval: The study was approved by the Institutional Ethics Committee

\section{REFERENCES}

1. Hunskaar S, Arnold EP, Burgio K, Diokno AC, Herzog AR, Mallett VT. Epidemiology and natural history of urinary incontinence. Int Urogynecol J. 2000;11(5):301-19.

2. Chmel R, Novácková M, Pastor Z, Vlk R, Horcicka L, Pluta $\mathrm{M}$, et al. Abdominal hysterectomy--risk factor in development of urinary incontinence? Results of a questionnaire study. Ceska Gynekol. 2005;70(1):53-6.

3. de Tayrac R, Chevalier N, Chauveaud-Lambling A, Gervaise A, Fernandez H. Is vaginal hysterectomy a risk factor for urinary incontinence at long-term follow-up? Eur J Obstet Gynecol Reprod Biol. 2007;130(2):258-61.

4. Brown JS, Sawaya G, Thom DH, Grady D. Hysterectomy and urinary incontinence: a systematic review. The Lancet. 2000;356(9229):535-9.

5. Duru C, Jha S, Lashen H. Urodynamic outcomes after hysterectomy for benign conditions: a systematic review and meta-analysis. Obstet Gynecol Surv. 2012;67(1):45-4.

6. Hsieh $\mathrm{CH}$, Chang WC, Lin TY, Su TH, Li YT, Kuo $\mathrm{TC}$, et al. Long-term effect of hysterectomy on urinary incontinence in Taiwan. Taiwan J Obstet Gynecol. 2011;50(3):326-30.

7. Miller J-JR, Botros SM, Beaumont JL, Aschkenazi SO, Gamble T, Sand PK, et al. Impact of hysterectomy on stress urinary incontinence: an identical twin study. Am J Obstet Gynecol. 2008 May;198(5):565.e1-4.

8. Haylen BT, Freeman RM, Swift SE, Cosson M, Davila GW, Deprest J, et al. An International Urogynecological Association (IUGA)/International Continence Society (ICS) joint terminology and classification of the complications related directly to the insertion of prostheses (meshes, implants, tapes) and grafts in female pelvic floor surgery. Neurourol Urodyn. 2011;30(1):2-12.

9. Van der VCH, Van der BJG, de Leeuw JR. J., Roovers J PWR, Heintz APM. The contribution of hysterectomy to the occurrence of urge and stress urinary incontinence symptoms. BJOG Int J Obstet Gynaecol. 2002;109(2):149-54. 
10. Gustafsson C, Ekström A, Brismar S, Altman D. Urinary incontinence after hysterectomy--three-year observational study. Urology. 2006;68(4):769-74.

11. Kudish BI, Shveiky D, Gutman RE, Jacoby V, Sokol AI, Rodabough R, et al. Hysterectomy and urinary incontinence in postmenopausal women. Int Urogynecol J. 2014;25(11):1523-31.

12. Hillard T. The postmenopausal bladder.Menopause 2010;16(2):74-80.

13. El-Toukhy TA, Hefni MA, Davies AE, Mahadevan S. The effect of different types of hysterectomy on urinary and sexual functions: a prospective study. J Obstet Gynaecol. 2004;24(4):420-5.

14. Li PC, Huang HK, Ding DC. Hysterectomy associated with de novo lower urinary tract symptoms in a Taiwanese population: a nationwide, population-based study. Int Urogynecol J. 2018:1-7.

15. Bunn F, Kirby M, Pinkney E, Cardozo L, Chapple C, Chester $\mathrm{K}$, et al. Is there a link between overactive bladder and the metabolic syndrome in women? A systematic review of observational studies. Int J Clin Pract. 2015;69(2):199-217.

16. Gorbachinsky I, Akpinar H, Assimos DG. Metabolic Syndrome and Urologic Diseases. Rev Urol. 2010;12(4):e157-80.

17. He Q, Wang Z, Liu G, Daneshgari F, MacLennan GT, Gupta S. Metabolic syndrome, inflammation and lower urinary tract symptoms-Possible translational links. Prostate Cancer Prostatic Dis. 2016;19(1):7.

18. Hong GS, Shim BS, Chung WS, Yoon H. Correlation between metabolic syndrome and lower urinary tract symptoms of males and females in the aspect of gender-specific medicine: a single institutional study. Korean J Urol. 2010;51(9):631-5.

19. Otunctemur A, Dursun M, Ozbek E, Sahin S, Besiroglu H, Koklu I, et al. Impact of metabolic syndrome on stress urinary incontinence in pre- and postmenopausal women. IntUrolNephrol. 2014;46(8):1501-5.

20. Tai HC, Chung SD, Ho CH, Tai TY, Yang WS, Tseng C-H, et al. Metabolic Syndrome Components Worsen Lower Urinary Tract Symptoms in Women with Type 2 Diabetes. J Clin Endocrinol Metab. 2010;95(3):1143-50.

21. Uzun H, Zorba OÜ. Metabolic Syndrome in Female Patients with Overactive Bladder. Urol. 2012;79(1):72-5.
22. Kirss F, Lang K, Toompere K, Veerus P. Prevalence and risk factors of urinary incontinence among Estonian postmenopausal women. Springerplus. 2013;2(1):524.

23. Brown JS, Grady D, Ouslander JG, Herzog AR, Varner RE, Posner SF. Prevalence of urinary incontinence and associated risk factors in postmenopausal women. Obstet Gynecol. 1999;94(1):66-70.

24. Singh A. Incidence and epidemiology of urinary incontinence in women. J Obstet Gynaecol India. 2007;57(2):155-7.

25. Danforth KN, Townsend MK, Lifford K, Curhan GC, Resnick NM, Grodstein F. Risk factors for urinary incontinence among middle-aged women. Am J Obstet Gynecol. 2006;194(2):339-45.

26. Liu B, Wang L, Huang S-S, Wu Q, Wu D-L. Prevalence and risk factors of urinary incontinence among Chinese women in Shanghai.Int J Clin Exp Med. 2014;7(3):686-96.

27. Schreiber PL, Lose G, Høybye MT, Elsner S, Waldmann A, Rudnicki M. Prevalence of urinary incontinence among women and analysis of potential risk factors in Germany and Denmark. Acta Obstet Gynecol Scand. 2017;96(8):939-48.

28. Hock M, Tóth S, Hartmann G, Hartmann T, Bódis J, Garai J. Quality of Life, Sexual Functions and Urinary Incontinence After Hysterectomy in Hungarian Women. Am J Health Res. 2015;3(6):393-8.

29. Zacche MM, Giarenis I, Thiagamoorthy G, Robinson D, Cardozo L. Is there an association between aspects of the metabolic syndrome and overactive bladder? A prospective cohort study in women with lower urinary tract symptoms. Eur J Obstet Gynecol Reprod Biol 2017;217:1-5.

Cite this article as: Alexander MC, Londhe V, Ebenezer ED, Kekre AN, Jeyaseelan V. Is hysterectomy a risk factor for urinary incontinence? Int J Reprod Contracept Obstet Gynecol 2019;8:1260-5. 